\title{
The accelerometer-based navigation system demonstrated superior radiological outcomes in restoring mechanical alignment and component sagittal positioning in total knee arthroplasty
}

Jiaxiang Gao ${ }^{1,2+}$, Yunfei Hou ${ }^{1,2+}$, Rujun Li ${ }^{1,2}$, Yan Ke ${ }^{1,2}$, Zhichang Li ${ }^{1,2^{*}}$ and Jianhao Lin ${ }^{1,2^{*}}$

\begin{abstract}
Background: This study aimed to determine whether the accelerometer-based navigation (ABN) could improve the accuracy of restoring mechanical axis (MA), component positioning, and clinical outcomes compared to conventional (CON) total knee arthroplasty (TKA).

Methods: A total of 301 consecutive patients (ABN: 27, CON: 274) were included. A 1:4 propensity score matching (PSM) was performed between the two groups according to preoperative demographic and clinical parameters. The postoperative MA, femoral coronal angle (FCA), femoral sagittal angle (FSA), tibial coronal angle (TCA) and tibial sagittal angle (TSA) were compared. Absolute deviations of aforementioned angles were calculated as the absolute value of difference between the exact and ideal value and defined as norms if within $3^{\circ}$, otherwise regarded as outliers. Additional clinical parameters, including the Knee Society knee and function scores (KSKS and KSFS) and range of motion (ROM), were assessed at final follow-up (FU) (mean FU was 21.88 and 21.56 months respectively for ABN and CON group). A secondary subgroup analysis and comparison on clinical outcomes were conducted between norms and outliers in different radiological parameters.

(Continued on next page)
\end{abstract}

\footnotetext{
*Correspondence: li_zhichang@pkuph.edu.cn; linjianhao@pkuph.edu.cn

${ }^{\dagger}$ Jiaxiang Gao and Yunfei Hou are co-first authors.

'Arthritis Clinic \& Research Center, Peking University People's Hospital, Peking University, Beijing 100044, China

Full list of author information is available at the end of the article
}

C C The Author(s). 2021 Open Access This article is licensed under a Creative Commons Attribution 4.0 International License, which permits use, sharing, adaptation, distribution and reproduction in any medium or format, as long as you give appropriate credit to the original author(s) and the source, provide a link to the Creative Commons licence, and indicate if changes were made. The images or other third party material in this article are included in the article's Creative Commons licence, unless indicated otherwise in a credit line to the material. If material is not included in the article's Creative Commons licence and your intended use is not permitted by statutory regulation or exceeds the permitted use, you will need to obtain permission directly from the copyright holder. To view a copy of this licence, visit http://creativecommons.org/licenses/by/4.0/ The Creative Commons Public Domain Dedication waiver (http://creativecommons.org/publicdomain/zero/1.0/) applies to the data made available in this article, unless otherwise stated in a credit line to the data. 
(Continued from previous page)

Results: A total of 98 patients/102 knees were analyzed after the PSM (ABN: 21 patients/24 knees, CON: 77 patients/78 knees). In the ABN group, the mean MA, FCA and TSA were significantly improved ( $p=0.019$, $0.006,<0.001$, respectively). Proportions of TKAs within $a \pm 3^{\circ}$ deviation were significantly improved in all the postoperative radiological variables except for TCA $(p=0.003,0.021,0.042,0.013$, respectively for MA, FCA, FSA, and TSA). The absolute deviations of FSA and TSA were also significantly lower in the $\operatorname{ABN}$ group $(p=0.020$, 0.048 , respectively). No significant differences were found in either mean value, absolute deviation or outlier ratio of TCA between two groups. On clinical outcomes, there were no significant differences between two groups, although KSKS, KSFS and $\operatorname{ROM}(p<0.01$, respectively) dramatically improved compared to baseline. The subgroup analysis also demonstrated no statistical difference on clinical outcomes between the outliers and norms in varied radiological parameters.

Conclusions: The ABN could improve the accuracy and precision of mechanical alignment and component positioning without significant improvement of clinical outcomes. Further high quality studies with long term FU are warranted to comprehensively evaluate the value of the $A B N$.

Keywords: Total knee arthroplasty, Accelerometer-based navigation, Mechanical axis, Component sagittal positioning

\section{Background}

In total knee arthroplasty (TKA), both optimal mechanical alignment (MA) and component positioning will influence the outcomes [1]. It has been found that malalignment of greater than $3^{\circ}$ would lead to apparent polyethylene wear [1] and premature failure [2], with a rising revision rate as high as $24 \%$ [3]. The accuracy of conventional technique on bone resection might be restricted in cases with obvious extra-articular deformities (EAD), excessive anterior femoral bowing and etc. [4]. The outliers ratio within these above mentioned challenging clinical scenarios may be as high as 22 to 35\% [5].

With the aiming of improving accuracy and precision of overall limb alignment as well as component positioning in TKA, computer-assisted surgery (CAS) has rapidly developed and been well applied. Based on the Australian Orthopaedic Association National Joint Replacement Registry (AOANJRR), the rate of CAS navigation has increased from $2.4 \%$ in 2003 to $30.8 \%$ in 2016 [6]. Also De Steiger et.al found a significant decrease of the revision rate for aseptic loosening in the CAS-navigated group for patients $<65$ years old over a 9-year follow-up (FU) [7]. Generally, three categories of CAS can be defined: image-based largeconsole navigation; imageless large-console navigation, and more recently, handheld accelerometer-based navigation $(\mathrm{ABN})$ systems have been developed [8]. It has been demonstrated to provide a similar level of accuracy and precision at achieving a predefined alignment goal as large-console CAS, both of which are more accurate than conventional techniques using intramedullary or extramedullary instrumentation [9].

Disadvantages of large-console CAS includs higher economic costs, increased operative time, longer learning curve, and pin site complications (such as pain, wound drainage, infection, and rarely but devastatingly, fracture) [8]. While the typical workflow of handheld $\mathrm{ABN}$ devices provides a more similar feel to conventional intra/extramedullary alignment jigs and digital feedback as well as anatomical landmark referencing, with a minimal additional operation time and relatively low cost [10]. Previous studies [11-15] have evaluated the MA and component positions after TKA with $A B N$, the outlier rates of varied radiological parameters and clinical outcomes between navigation and conventional-technique groups have also been compared. However none of the previous studies evaluated the clinical outcomes between outliers and norms. The primary objective of this retrospective, propensity score-matched comparative study was to compare the postoperative radiological and clinical outcomes between patients undertaking TKA with the $\mathrm{ABN}$ system and conventional techniques. A subgroup analysis and comparison of clinical outcomes between outliers and norms have also been conducted as secondary objectives of the current study.

\section{Methods \\ Patient selection}

A retrospective review of institutional medical record database was conducted, which was approved by the local Ethics Committee of Peking University People's Hospital (2020PHB171-01). Consecutive cases of patients who received a primary posterior-stabilized (PS) TKA by using either iAssist (Zimmer, Warsaw, IN) navigation system (ABN group) or conventional techniques (CON group) from May 2017 to September 2019 were included. Exclusion criteria included: (1) hip and/or ankle pathology with a severe limited range of motion (ROM) (2) or causing severe functional limitations, (3) patients lost to follow-up. The surgery was performed by one experienced arthroplasty surgeon (LJH). 


\section{Data collection}

Preoperative demographic data was collected. Preoperative Knee Society knee scores (KSKS) and function scores (KSFS) and ROM were also recorded.

\section{Surgical technique}

The primary difference on surgical techniques exclusively existed in bone cutting, except for which, all other surgical procedures, i.e. approach (medial parapatellar approach), soft tissue balancing (gap balancing technique) and cementing techniques remained the same between both groups. In the ABN group, the surgeon followed the instructions based on the surgical technique manual of the iAssist system. A validation procedure was performed following every cut and make additional adjustments when necessary.

As for the CON group, standard intramedullary alignment technique on femoral side and extra-medullary alignment technique on tibial side were used. Preoperative radiographs, including weight-bearing anteroposterior (AP) view, lateral view and long-leg standing AP film, were referred to preoperatively.

\section{Radiological evaluation}

Radiological assessment was carried out by utilizing standardized postoperative radiographs, including longleg standing AP film, along with AP and lateral knee films [16]. All electronic radiographs were analyzed and measured by 2 independent observers (GJX and HYF) who had not participated in the surgery and been blinded to the allocation of groups. The radiographs were assessed twice, more than 2 weeks apart for each observer. The intra- and inter-observer reliability were evaluated and rated based on the method described by Konigsberg et al. [17]. The intra-observer reliability based on intra-class correlation coefficient (ICC) were 0.972 (95\% CI: 0.965 to 0.978 ) and 0.942 (95\% CI: 0.928 to 0.954 ), respectively for the two observers. For interobserver reliability, the ICC was 0.953 (95\% CI: 0.941 to 0.962).

Three radiographic measurements were carried out on the AP hip-to-ankle radiographs (Fig. 1a): (1) lower extremity MA, which was formed by the angle bisecting the center of the femoral head, the center of the knee joint, and the center of the talus [12]; (2) femoral coronal angle (FCA), the lateral angle between femoral MA and intercondylar line; (3) tibial coronal angle (TCA), the medial angle between the tibial MA and the line parallel to the tibial tray. Two measurements were performed on the lateral films (Fig. 1b): (1) femoral sagittal angle (FSA), the posterior angle between the anterior cortical axis (the line linking two points of the anterior cortex at 5 and $15 \mathrm{~cm}$ proximal to the joint line [18]) of femur and the slope of distal femoral cut; (2) tibial sagittal angle (TSA), the posterior angle between the proximal anatomical axis (the line linking midpoints of outer cortical diameter at 5 and $15 \mathrm{~cm}$ distal to the knee joint [19]) of tibia and the slope of the proximal tibial cut. Absolute deviations of aforementioned angles were calculated as the absolute value of difference between the exact and ideal value (MA, $0^{\circ}$; FCA, $90^{\circ}$; TCA, 90 FSA, $87^{\circ}$; TSA, $83^{\circ}$ [20]). In line with the consensus of most research, absolute deviations of these angles were defined as norms if within $3^{\circ}$, otherwise they were regarded as outliers [21-23].

\section{Clinical evaluation}

Clinical outcomes were assessed using the KSKS and KSFS [24], as well as ROM, which was measured by a goniometer on the basis of the active maximum knee ROM. All the clinical outcomes were collected by two co-authors (LZC and LRJ) who were blinded to the patient group.

\section{Propensity-matched analysis}

Propensity score matching (PSM) analysis is a statistical technique aiming to minimize the effects of confounding factors attributable to measured covariates [25]. A propensity score was defined to be a patient's conditional likelihood of being assigned a treatment based upon patient's pre-treatment characteristics by logistic regression using the R (V.3.6.1) package "MatchIt" (V. 3.0.2) and "tableone" (V.0.10.0). In this particular study, PSM was conducted between the ABN group and the CON group with a 1:4 ratio, rather than a 1:1 ratio in order to increase precision [26]. A caliper of 0.02 , based on age, gender, side of surgery, body mass index (BMI), ROM, KSKS and KSFS scores along with preoperative MA at baseline, was used in the PSM process.

\section{Statistical comparisons}

Radiological and clinical data were compared between the $\mathrm{ABN} \& \mathrm{CON}$ groups. Clinical outcomes were also compared between outliers and norms in different radiological parameters, as secondary subgroup analysis. Continuous data (age, BMI, ROM, KSKS, KSFS, MA, FCA, TCA, FSA, and TSA), were presented as means \pm standard deviations (SD) and compared by utilizing either Student's $\mathrm{t}$ test (for normally distributed data with equal variances), Welch's $t$ test (for normally distributed data with unequal variances), or the Mann-Whitney $U$ test (for non-normally distributed data). While the categorical data (gender, side of surgery, prosthesis type, and outlier ratio) were presented as counts and percentages, for which Fisher's exact test (when expected count was less than 5) or Chi-Square-test (when expected count was no less than 5) was used to compare between groups. Specifically, gender, prosthesis type and outlier 


\section{a}

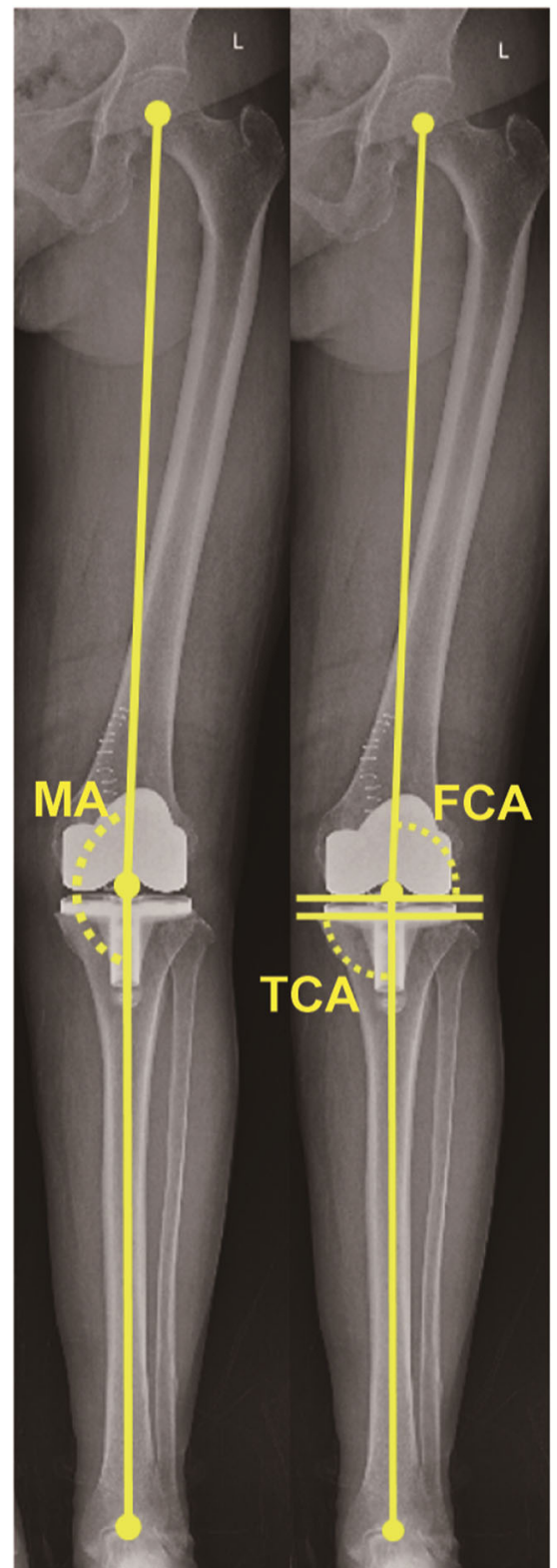

b

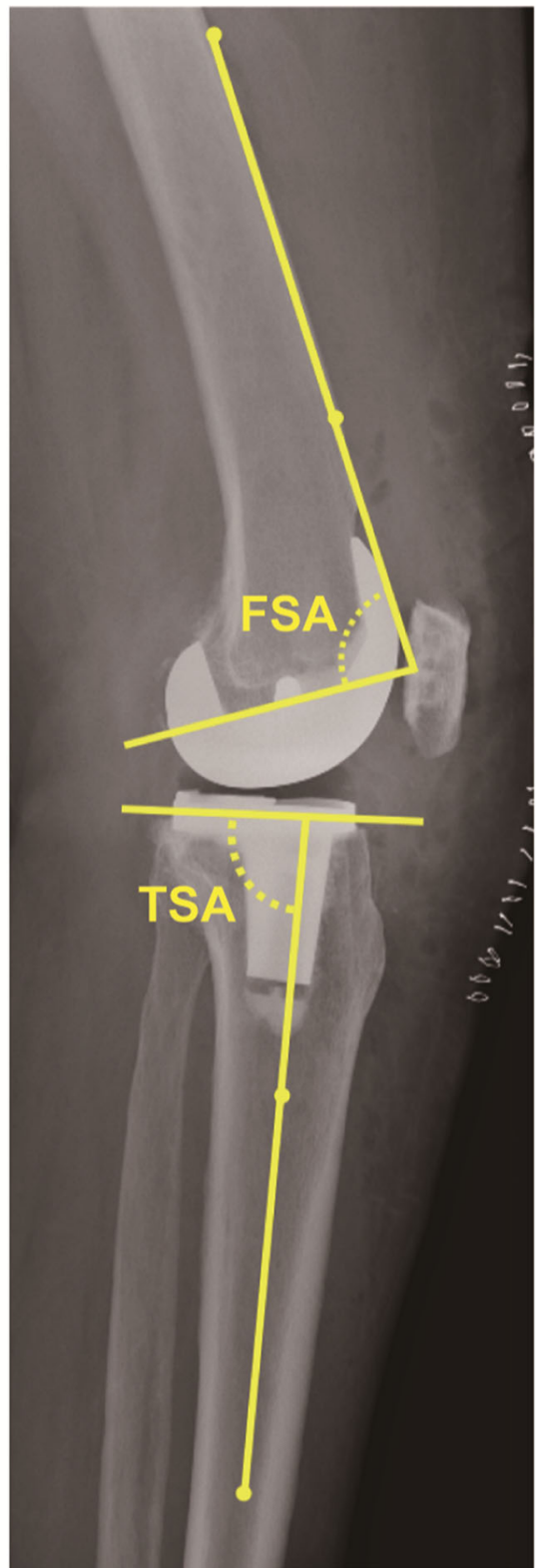

Fig. 1 a Long-leg standing AP film for radiographic measurements in the coronal plane, including MA, FCA, and TCA. b Lateral radiograph for measuring component alignments in the sagittal plane, including FSA and TSA. Abbreviations, MA, mechanical axis; FCA, femoral coronal angle; TCA, tibial coronal angle; FSA, femoral sagittal angle; TSA, tibial sagittal angle

ratio of TCA were compared using Fisher's exact test, while the rest of categorical variables were analyzed by Chi-Square-test. Pre- and post-operative comparisons were also conducted for clinical parameters using paired $\mathrm{t}$-test. To adjust for the pre-operative baseline of clinical outcomes (KSKS, KSFS, and ROM), analysis of covariance (ANCOVA) was used to detect differences between groups. Statistical comparisons were conducted using SPSS (version 20.0; IBM SPSS Statistics, Chicago, IL, USA), with statistical significance set at $p<0.05$.

\section{Results}

\section{Patient characteristics}

A total of 301 patients/332 knees were included in this study (ABN group: 27 patients/33 knees, CON group: 274 patients/299 knees). After PSM analysis, 98 patients/ 102 knees were finally included for analysis (ABN group: 21 patients/24 knees; CON group: 77 patients/78 knees). Demographic data before and after PSM were summarized in Table 1, revealing no significant differences in all demographic and clinical data after matching. By the 
Table 1 Demographic characteristic of included patients

\begin{tabular}{|c|c|c|c|c|c|c|}
\hline & \multicolumn{2}{|c|}{ Unmatched group } & \multirow[t]{2}{*}{$P$ value } & \multicolumn{2}{|c|}{ Propensity-matched group } & \multirow[t]{2}{*}{$P$ value } \\
\hline & $A B N$ group & CON group & & $A B N$ group & CON group & \\
\hline Number of cases/ knees & $27 / 33$ & $274 / 299$ & & $21 / 24$ & $77 / 78$ & \\
\hline Age (years) & $70.52 \pm 6.50$ & $69.36 \pm 7.00$ & 0.368 & $71.04 \pm 6.75$ & $69.18 \pm 7.33$ & 0.270 \\
\hline Gender (female) & $31(93.9 \%)$ & $234(78.3 \%)$ & $0.033^{*}$ & $22(91.7 \%)$ & $68(87.2 \%)$ & 0.727 \\
\hline Knee (right) & $16(48.5 \%)$ & $122(40.8 \%)$ & 0.507 & $10(41.7 \%)$ & 35 (44.9\%) & 0.967 \\
\hline Prosthesis type & & & $0.040^{*}$ & & & 0.137 \\
\hline LPS-Flex & $29(87.9 \%)$ & $198(66.2 \%)$ & & $21(87.5 \%)$ & $51(65.4 \%)$ & \\
\hline Legion PS & $2(6.1 \%)$ & $53(17.7 \%)$ & & $1(4.2 \%)$ & $14(17.9 \%)$ & \\
\hline Attune PS & $2(6.1 \%)$ & $48(16.1 \%)$ & & $2(8.3 \%)$ & $13(16.7 \%)$ & \\
\hline BMI (kg/m2) & $27.12 \pm 2.87$ & $26.88 \pm 3.72$ & 0.718 & $27.80 \pm 2.85$ & $27.40 \pm 3.54$ & 0.615 \\
\hline KSKS & $42.24 \pm 14.75$ & $40.41 \pm 16.17$ & 0.534 & $40.79 \pm 15.21$ & $39.79 \pm 16.26$ & 0.790 \\
\hline KSFS & $46.06 \pm 22.94$ & $52.93 \pm 20.75$ & 0.075 & $46.46 \pm 19.31$ & $49.88 \pm 20.97$ & 0.478 \\
\hline $\mathrm{ROM}\left({ }^{\circ}\right)$ & $95.15 \pm 18.94$ & $95.20 \pm 19.90$ & 0.989 & $95.83 \pm 18.51$ & $93.08 \pm 22.15$ & 0.582 \\
\hline $\mathrm{MA}\left({ }^{\circ}\right)$ & $4.38 \pm 11.87$ & $9.50 \pm 11.87$ & $0.021^{*}$ & $7.80 \pm 8.76$ & $8.04 \pm 6.13$ & 0.882 \\
\hline FU time (month) & $21.79 \pm 1.65$ & $21.99 \pm 8.03$ & 0.754 & $21.88 \pm 1.42$ & $21.56 \pm 8.66$ & 0.725 \\
\hline
\end{tabular}

Abbreviations: BMI Body mass index, ROM Range of motion, KSKS Knee society knee score, KSFS Knee society function score, MA Mechanical axis (neutral MA $=0^{\circ}$, valgus $=$ negative, varus $=$ positive), FU Follow-up

$P$ value $<0.05$ were strengthened by *

time of final FU, there were no revision cases of any reasons within this group of 301 patients.

\section{Radiographic outcomes}

Table 2 presented all the aforementioned radiological variables of interest. In the $\mathrm{ABN}$ group, proportions of
TKAs within $\mathrm{a} \pm 3^{\circ}$ deviation were significantly higher in all postoperative radiological variables except for TCA $(p=0.003,0.021,0.042,0.013$, respectively for MA, FCA, FSA, and TSA). The absolute deviation of FSA and TSA were also significantly lower $(p=0.020,0.048$, respectively). The mean MA, FCA and TSA were significantly

Table 2 Radiographic outcomes between iAssist (ABN) group and conventional (CON) group

\begin{tabular}{llll}
\hline & ABN group $(\boldsymbol{n}=\mathbf{2 4})$ & CON group $(\boldsymbol{n}=\mathbf{7 8})$ & $\boldsymbol{P}$ value \\
\hline MA value & $0.32 \pm 2.17$ & $1.74 \pm 3.38$ & $0.019^{*}$ \\
MA absolute deviation & $1.85 \pm 1.12$ & $2.97 \pm 2.36$ & 0.058 \\
MA within $\pm 3^{\circ}(\mathrm{n}, \%)$ & $23(95.8 \%)$ & $51(65.4 \%)$ & $0.003^{*}$ \\
FCA value & $89.75 \pm 2.22$ & $91.66 \pm 3.09$ & $0.006^{*}$ \\
FCA absolute deviation & $1.66 \pm 1.45$ & $2.56 \pm 2.38$ & 0.145 \\
FCA within $90 \pm 3^{\circ}(\mathrm{n}, \%)$ & $22(91.7 \%)$ & $53(67.9 \%)$ & $0.021^{*}$ \\
TCA value & $89.53 \pm 1.76$ & $89.99 \pm 1.82$ & 0.287 \\
TCA absolute deviation & $1.38 \pm 1.15$ & $1.47 \pm 1.07$ & 0.507 \\
TCA within $90 \pm 3^{\circ}(n, \%)$ & $22(91.7 \%)$ & $74(94.9 \%)$ & 0.624 \\
FSA value & $88.79 \pm 1.90$ & $87.69 \pm 4.18$ & 0.311 \\
FSA absolute deviation & $2.10 \pm 1.49$ & $3.37 \pm 6.60$ & $0.020^{*}$ \\
FSA within $87 \pm 3^{\circ}(n, \%)$ & $18(75.0 \%)$ & $41(52.6 \%)$ & $0.042^{*}$ \\
TSA value & $83.22 \pm 2.27$ & $85.64 \pm 3.50$ & $<0.001^{*}$ \\
TSA absolute deviation & $1.89 \pm 1.21$ & $3.39 \pm 2.77$ & $0.048^{*}$ \\
TSA within $83 \pm 3^{\circ}(n, \%)$ & $21(87.5 \%)$ & $47(60.3 \%)$ & $0.013^{*}$ \\
\hline
\end{tabular}

Abbreviations: $M A$ Mechanical axis (optimal value $=0^{\circ}$, valgus = negative, varus = positive), $F C A$ Femoral coronal angle $\left(\right.$ optimal value $=90^{\circ}$ ), $T C A$ Tibial coronal angle (optimal value $=90^{\circ}$ ), FSA Femoral sagittal angle (optimal value $=87^{\circ}$ ), TSA Tibial sagittal angle $\left(\right.$ optimal value $=83^{\circ}$ )

$P$ value $<0.05$ were strengthened by * 
improved as well ( $p=0.019,0.006,<0.001$, respectively). In particular, no significant differences were found in all three statistical parameters of TCA between two groups.

\section{Short-term clinical outcomes}

All the clinical parameters significantly improved postoperatively comparing to the baseline in two groups $(p<0.001, \mathrm{p}<0.001, p=0.002$, respectively for KSKS, KSFS, and ROM in the ABN group; And $p<0.001$ for all 3 parameters in the CON group). Nevertheless, no significant differences were found in mean postoperative KSKS, KSFS and ROM (Table 3) between two groups. As for the changes of these clinical parameters from baseline, the differences were also not statistically different between two groups (Table 3). In the subgroup analysis of short-term clinical outcomes between the outliers and norms in varied radiological parameters, including the MA and component positioning (FCA, TCA, FSA, TSA), no statistical difference were found (Table 4).

\section{Discussion}

The current study demonstrated that with comparable clinical improvements in the $\mathrm{ABN}$ and the $\mathrm{CON}$ group, the iAssist system not only restored MA accurately and precisely, but also significantly improved prosthesis positioning, especially for the sagittal alignment of both femoral and tibial components.

With the exception of one study suggesting no significant difference in the ratio of outliers for lower limb alignment and component placement [14], the results of the present study were consistent with most published investigations comparing $\mathrm{ABN}$ with $\mathrm{CON}$ techniques [11-13, 15]. A prospective randomized controlled trial (RCT) found significant improvements in postoperative mean MA, FCA, and TCA, along with lower combined outlier ratios of femoral and tibial component $(4.0 \%$ in the $\mathrm{ABN}$ group, in comparison with $32 \%$ in the $\mathrm{CON}$ group) [12], though the authors did not analyze the

Table 3 Short-term clinical outcomes between iAssist (ABN) group and conventional (CON) group

\begin{tabular}{lccc}
\hline & ABN group & CON group & $P$ value \\
\hline \multicolumn{2}{c}{ Clinical outcomes at final FU } \\
KSKS & $90.38 \pm 10.45$ & $88.09 \pm 13.81$ & 0.487 \\
KSFS & $84.58 \pm 14.14$ & $84.48 \pm 14.96$ & 0.567 \\
ROM & $109.38 \pm 13.70$ & $109.71 \pm 16.78$ & 0.364 \\
\multicolumn{2}{l}{ Changes of clinical outcomes from preoperative baseline } \\
KSKS & $49.58 \pm 15.34$ & $48.30 \pm 15.32$ & 0.487 \\
KSFS & $38.13 \pm 16.67$ & $34.60 \pm 16.48$ & 0.567 \\
ROM & $11.79 \pm 16.72$ & $17.17 \pm 16.94$ & 0.364 \\
\hline
\end{tabular}

Abbreviations: KSKS Knee society knee scores, KSFS Knee society function scores, ROM Range of motion
Table 4 Subgroup analysis on clinical outcomes between outliers and norms

\begin{tabular}{llll}
\hline & MA norms $\left(\right.$ within $\left.\pm 3^{\circ}\right)$ & MA outliers & $P$ value \\
KSKS & $88.9 \pm 12.7$ & $88.0 \pm 14.3$ & 0.79 \\
KSFS & $84.7 \pm 15.5$ & $83.9 \pm 12.5$ & 0.53 \\
ROM & $109.1 \pm 15.7$ & $111.1 \pm 17.2$ & 0.45 \\
& FCA norms $\left(90 \pm 3^{\circ}\right)$ & FCA outliers & $P$ value \\
KSKS & $87.7 \pm 14.3$ & $91.3 \pm 8.5$ & 0.34 \\
KSFS & $83.9 \pm 15.9$ & $86.1 \pm 10.8$ & 0.81 \\
ROM & $109.0 \pm 16.5$ & $111.4 \pm 14.7$ & 0.57 \\
& FSA norms $\left(87 \pm 3^{\circ}\right)$ & FSA outliers & $P$ value \\
KSKS & $87.9 \pm 13.9$ & $89.6 \pm 11.9$ & 0.51 \\
KSFS & $82.8 \pm 16.1$ & $86.9 \pm 12.3$ & 0.24 \\
ROM & $109.2 \pm 15.6$ & $110.2 \pm 16.8$ & 0.82 \\
& TCA norms $\left(90 \pm 3^{\circ}\right)$ & TCA outliers & $P$ value \\
KSKS & $89.1 \pm 12.8$ & $83.3 \pm 16.4$ & 0.19 \\
KSFS & $84.7 \pm 14.7$ & $81.9 \pm 15.1$ & 0.56 \\
ROM & $110.0 \pm 15.8$ & $105.6 \pm 19.0$ & 0.55 \\
& TSA norms $\left(83 \pm 3^{\circ}\right)$ & TSA outliers & $P$ value \\
KSKS & $89.0 \pm 11.6$ & $87.9 \pm 15.7$ & 0.42 \\
KSFS & $84.0 \pm 15.5$ & $85.4 \pm 13.2$ & 0.80 \\
ROM & $109.0 \pm 16.0$ & $110.9 \pm 16.4$ & 0.58 \\
\hline Abbrviatons & KSKS Kne soi & &
\end{tabular}

Abbreviations: KSKS Knee society knee scores, KSFS Knee society function scores, ROM Range of motion, MA Mechanical axis, FCA Femoral coronal angle, TCA Tibial coronal angle, FSA Femoral sagittal angle, TSA Tibial sagittal angle

radiological variables in the sagittal plane. Nam et al. retrospectively compared the tibial component positioning between KneeAlign system, whose working rationale was similar to that of iAssist, with CON instrumentations, and observed fewer outliers for TCA and TSA as well [15]. Another retrospective comparative study also yielded similar results for restoring lower limb MA and achieving proper component positioning [13].

One crucial finding of the present was the superior efficacy of iAssist system for aligning the components in the sagittal plane. Sagittal plane positioning and alignment of component would affect patients' functional outcomes and prosthesis survivorship. Compared with a neutrally aligned implant, a slight-to-mid flexed femoral component could reduce the patellofemoral (PF) joint contact stress in PS-TKA [27]. However, an over-flexed femoral component, especially in patients of short stature, was associated with increased occurrence of persistent flexion contracture [28] and also impingement may occur between the post- and the femoral component [27]. Conversely, extraordinary femoral component extension might cause anterior knee pain in the long term [29]. Kim et.al highlighted the effect of femoral component's sagittal positioning on prosthesis survivorship and 
noted that a surgeon should intend to place the femoral component within $0-3^{\circ}$ flexion in the sagittal plane, if not, outliers would impact the component survival at a mean FU of 15.8 years [30]. Navigation was helpful in achieving an appropriate femoral sagittal alignment. While the flexion of femoral component was highly varied in conventionally aligned TKA [31], and a recommended femoral sagittal alignment of within $3^{\circ}$ flexion could be acquired in only $25 \%$ of the studied cases [32].

Studies have also demonstrated that the tibial slope related linearly to the postoperative ROM [33, 34], when the slope was within $10^{\circ}$, a $1^{\circ}$ increase would lead to a $2.6^{\circ}$ increase in the knee flexion angle for cruciateretaining (CR) TKA [34]. While excessively increased tibial slope might cause a greater contact stress on the tibial post, leading to increased polyethylene wear [35] as well as anterior impingement between the post and the femoral component, observed at near-full extension [36]. Iorio et.al found that traditional instrumentations failed to achieve ideal tibial component positioning, with a tendency towards decreased tibial slope [37].

In the current study and similar investigations [12, 14, 38 ], there were outliers as well in the ABN group despite validation procedure being performed. Hasegawa et.al defined these deviations between the radiographic and intraoperative component angles as radiographic errors [39]. In their study, the mean absolute tibial radiographic error were $0.8 \pm 1.0^{\circ}$ and $1.3 \pm 1.1^{\circ}$ in the coronal and sagittal planes, respectively. While the mean absolute error of the MA was $1.9 \pm 1.2^{\circ}$. There were several proposed reasons for these outliers. First, uneven cementation and impaction of components can introduce considerable errors regardless of how accurately the resection planes are made $[40,41]$. Second, large movements of the thigh, especially adduction, during the femoral registration, will induce anterior lift of the femoral head [42], introducing hip center registration errors. Any movement of the pelvis during circumduction could cause hip center rotation definition errors too [43]. Additionally, a stiff hip due to any aetiology that precludes an unrestricted hip circumduction is another plausible cause of hip center errors [44], though in the current study, such patients were excluded for analysis. Similarly, errors in ankle center registration may be responsible for tibial component outliers [44]. Third, sometimes the surgeon had accepted residual malalignment during surgery as understood from the navigation data to obtain a balanced extension and/or flexion space. Fourth, the outliers could be created from unstable trackers. Lastly, for patients with tibia vara deformity, tibial component is likely to be in valgus alignment (approximately $1^{\circ}$ ) even if a neutral angle $\left(0^{\circ}\right)$ has been selected in the procedure [42]. The deformity could cause medial positioning of the tibial eminence against the tibial shaft, which would consequently produce a shift of the tibial MA identified by the system [45].

On clinical outcomes, we found no significant differences in KSS and ROM between two groups, which was consistent with existing literatures. Liow et.al found no differences in both KSS and Oxford Knee Score (OKS) between the iAssist and the conventional group at 6 months postoperatively [13]. Another cohort study also demonstrated no differences in ROM, KSS and OKS following TKA between the two groups at both 6 months and 2 year FU [38]. Additionally, we observed no statistical differences between outliers and norms in all radiographic parameters. These results may raise a concern that the outlier reduction might not lead to incremental improvements in clinical outcomes in short term, which would make scholars overlook the role of $\mathrm{ABN}$ or CAS. In this study, we have used the widely accepted standard to define outliers as deviations of $3^{\circ}$. However, $3^{\circ}$ is an arbitrary figure rather than a genuine cut-off value for malalignment $[21,46]$. A spectrum probably exists, with a higher probability of failure as malalignment increases, probably due to excessive strain, eccentric loading and subsequent polyethylene wear or trabecular collapse [47-49]. Considering the results of these laboratory studies, we cautiously hold positive attitudes towards the value of $A B N$ TKA surgery, which might translate into improved survival in investigations with a long term FU. According to the AOANJRR report, a total of 114,859 navigated TKA with better postoperative component alignment showed a reduced 10-year revision rate and a significant reduction in revision secondary to component loosening [7]. Another study with 15.8-year FU also showed that malalignment was a risk factor for failure of the components in the long term [30].

The value of navigation could also lie on implementing individualized and kinematic alignment (KA) TKA, whose main purpose and rationale is to restore a patient-specific and native pre-arthritic knee alignment and anatomy [50-52]. Compared to the traditional MA technique, KA could achieve better PF [53] and tibiofemoral joint biomechanics [54] and thus better patient preference [55]. Furthermore, KA TKAs were able to achieve the same degree of sagittal correction as MA techniques with less bony resection and soft-tissue releases [56]. Additionally, the 10-year implant survival of KA TKA was not compromised [57].

From the health economics standpoint, the value of new technology including computer navigation could be defined as the benefit divided by the cost [58]. Based on 2007 costings, Novak et al. employed a decision-analysis model to estimate the cost-effectiveness of CAS navigation in TKA, determining that cost-savings could be achieved in the long-term if the cost of CAS navigation was $\$ 629$ or less per operation [59]. Thus selective use 
of the $A B N$ would be an optimal strategy, we proposed several suitable indications of the $A B N$ based on our clinical experiences and previous research. For patients with a femoral or tibial EAD, being accurate could be technically demanding [33], in which cases surgeons might fail to figure out the proper valgus cut angle of distal femur (Fig. 2a). In such cases, the ABN system appeared to be valuable [60]. Individuals with lower limb fracture malunion may develop EAD and/or have hardware (Fig. 2b). It was also a potential advantage of the $\mathrm{ABN}$ to obtain the desired component positions without irritating the medullary. In the similar rationale, the surgery was performed for one patient with benign bone tumor in distal femur uneventfully with the use of iAssist, without offending the tumor (Fig. 2c). Moreover, for individuals with extraordinary anterior femoral bowing, similar to those with an EAD, femoral component flexion would have a significant increase [61]. Utilising ABN could also make sense.

Another important strategy is to minimize the technical errors within navigation TKA, based on potential reasons for the errors, surgeons should make sure that trackers are always stable. Small movements without excessive forces during registration is recommended and lastly surgeons should perform a meticulous cementation technique. One should also notice that there are higher chances of creating technical errors in patients with a stiff hip or obvious tibia vara deformity.

There were several limitations of this study. First, it was a retrospective study in nature, and selection bias existed. We mitigate the negative effects by utilizing the PSM analysis, to minimize the inherent bias produced from covariates, and further lower the influence of confounding factors. Second, the FU period was relatively short. In order to explore the effect of $\mathrm{ABN}$ system in a more comprehensive fashion, future prospective studies focusing on radiological, functional and survival outcomes with longer FU are warranted. Third, only lateral knee films but not lateral long leg standing X-ray were available and used when assessing the FSA. Although the authors concluded that there were only small differences between anatomical and mechanical sagittal femur axes [14], using the short film would inevitably generate measurement errors. Finally, only two male patients undertook primary TKA with the iAssist system during May 2017 to September 2019, which seemed to be a coincidence accounting for this great gender disparity.

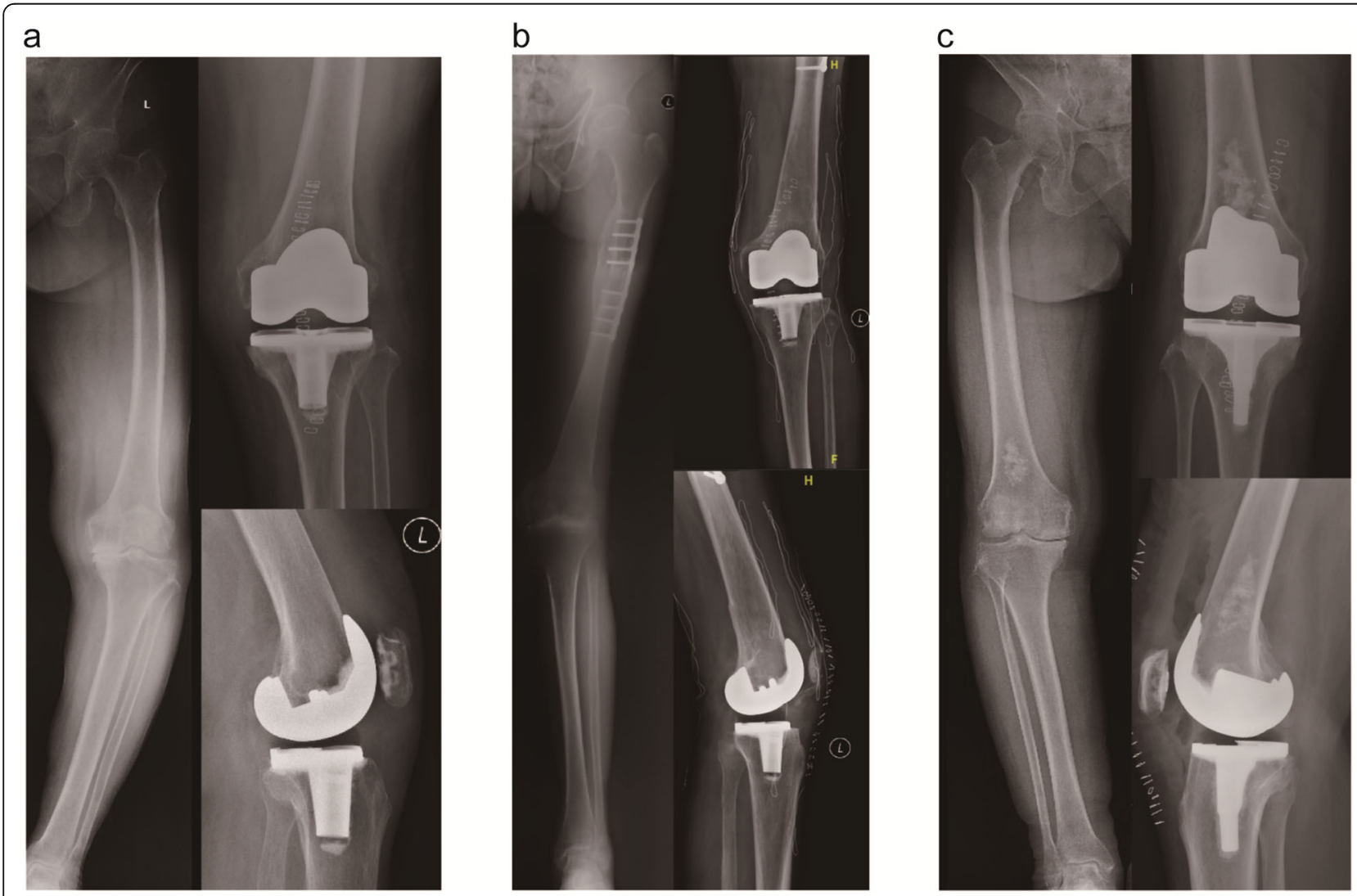

Fig. 2 a Pre- and postoperative radiographs of patient with femoral EAD. b Pre- and postoperative radiographs of patient with lower limb fracture malunion and hardware retaining. c Pre- and postoperative radiographs of patient with benign bone tumor in distal femur 


\section{Conclusions}

Although clinical differences were not observed either between the $A B N$ and $C O N$ group, or between the outliers and norms, the results of the current study demonstrated that the use of $\mathrm{ABN}$ aided in achieving better radiological results including postoperative $\mathrm{MA}$ and component positioning, especially for sagittal component alignment (FSA and TSA). Two essential strategies (selecting optimal patients and reducing technical errors) were provided and discussed in order to maximize the value of $A B N$ in TKA.

\begin{abstract}
Abbreviations
ABN: Accelerometer-based navigation; MA: Mechanical axis; CON: Conventional; TKA: Total knee arthroplasty; PSM: Propensity score matching; FCA: Femoral coronal angle; FSA: Femoral sagittal angle; TCA: Tibial coronal angle; TSA: Tibial sagittal angle; KSKS: Knee Society knee scores; KSFS: Knee Society function scores; ROM: Range of motion; FU: Follow-up; EAD: Extra-articular deformities; CAS: Computer-assisted surgery; AOANJRR: Australian Orthopaedic Association National Joint Replacement Registry; PS: Posterior-stabilized; AP: Anteroposterior; ICC: Intraclass correlation coefficient; SD: Standard deviations; ANCOVA: Analysis of covariance; RCT: Randomized controlled trial; PF: Patellofemoral; CR: Cruciateretaining; OKS: Oxford Knee Score
\end{abstract}

\section{Acknowledgements}

The authors thank Liyi Zhang for statistical input when collecting the data.

\section{Authors' contributions}

Study design: JX Gao and YF Hou. Data collection/validation: JX Gao, YF Hou and ZC Li. Data analysis: JX Gao and ZC Li. Result interpretation: JX Gao, YF Hou and RJ Li. Reporting \& editing: JX Gao, YF Hou, Y Ke and JH Lin. Final approval of the version to be submitted: JX Gao, YF Hou, JH Lin. Project guarantor: JH Lin. The authors read and approved the final manuscript.

\section{Funding}

None.

\section{Availability of data and materials}

All of the data will be available for secondary analysis in necessary cases from the corresponding author through email address.

\section{Declarations}

\section{Ethics approval and consent to participate}

All procedures performed in this study were in accordance with the ethical standards of the institutional and national research committee and with 1964 Helsinki declarations and its later amendments. The study commenced after receiving its ethical approval from the institutional review board of Peking University People's Hospital (2020PHB171-01). Written informed consent was obtained from all of the patients before the surgery.

\section{Consent for publication}

Written informed consent for publication was obtained from all participants.

\section{Competing interests}

The authors declare that they have no conflict of interests.

\section{Author details}

${ }^{1}$ Arthritis Clinic \& Research Center, Peking University People's Hospital, Peking University, Beijing 100044, China. ${ }^{2}$ Arthritis Institute, Peking University, Beijing, China.
Received: 27 November 2020 Accepted: 30 March 2021

Published online: 13 April 2021

\section{References}

1. Longstaff LM, Sloan K, Stamp N, Scaddan M, Beaver R. Good alignment after total knee arthroplasty leads to faster rehabilitation and better function. J Arthroplast. 2009;24(4):570-8. https://doi.org/10.1016/j.arth.2008.03.002.

2. Moreland JR. Mechanisms of failure in total knee arthroplasty. Clin Orthop Relat Res. 1988:226:49-64.

3. Huang EH, Copp SN, Bugbee WD. Accuracy of a handheld accelerometerbased navigation system for femoral and Tibial resection in Total knee arthroplasty. J Arthroplast. 2015;30(11):1906-10. https://doi.org/10.1016/j.a rth.2015.05.055.

4. Anderson KC, Buehler KC, Markel DC. Computer assisted navigation in total knee arthroplasty: comparison with conventional methods. J Arthroplast. 2005;20(7 Suppl 3):132-8. https://doi.org/10.1016/j.arth.2005.05.009.

5. Blakeney WG, Khan RJ, Wall SJ. Computer-assisted techniques versus conventional guides for component alignment in total knee arthroplasty: a randomized controlled trial. J Bone Joint Surg Am. 2011;93(15):1377-84. https://doi.org/10.2106/jbjs.l.01321.

6. National Joint Replacement Registry AOA Hip, Knee \& Shoulder Arthroplasty 2017 Annu Rep 2017

7. de Steiger RN, Liu YL, Graves SE. Computer navigation for total knee arthroplasty reduces revision rate for patients less than sixty-five years of age. J Bone Joint Surg Am. 2015;97(8):635-42. https://doi.org/10.2106/jbjs.M.01496.

8. Jones CW, Jerabek SA. Current role of computer navigation in Total knee arthroplasty. J Arthroplast. 2018;33(7):1989-93. https://doi.org/10.1016/j.a rth.2018.01.027.

9. Laskin RS, Beksaç B. Computer-assisted navigation in TKA: where we are and where we are going. Clin Orthop Relat Res. 2006;1:452127-31. https://doi. org/10.1097/01.blo.0000238823.78895.dc.

10. Goh GS, Liow MH, Lim WS, Tay DK, Yeo SJ, Tan MH. Accelerometer-based navigation is as accurate as optical computer navigation in restoring the joint line and mechanical Axis after Total knee arthroplasty: a prospective matched study. J Arthroplast. 2016;31(1):92-7. https://doi.org/10.1016/j.arth.2 015.06.048.

11. Gao X, Sun Y, Chen ZH, Dou TX, Liang QW, Li X. Comparison of the accelerometer-based navigation system with conventional instruments for total knee arthroplasty: a propensity score-matched analysis. J Orthop Surg Res. 2019;14(1):223. https://doi.org/10.1186/s13018-019-1258-y.

12. Kinney MC, Cidambi KR, Severns DL, Gonzales FB. Comparison of the iAssist handheld guidance system to conventional instruments for mechanical Axis restoration in Total knee arthroplasty. J Arthroplast. 2018;33(1):61-6. https:// doi.org/10.1016/j.arth.2017.06.004

13. Liow MH, Goh GS, Pang HN, Tay DK, Lo NN, Yeo SJ. Computer-assisted stereotaxic navigation improves the accuracy of mechanical alignment and component positioning in total knee arthroplasty. Arch Orthop Trauma Surg. 2016:136(8):1173-80. https://doi.org/10.1007/s00402-016-2483-z.

14. Moo IH, Chen JYQ, Chau DHH, Tan SW, Lau ACK, Teo YS. Similar radiological results with accelerometer-based navigation versus conventional technique in total knee arthroplasty. J Orthop Surg (Hong Kong). 2018;26(2): 2309499018772374. https://doi.org/10.1177/2309499018772374.

15. Nam D, Cody EA, Nguyen JT, Figgie MP, Mayman DJ. Extramedullary guides versus portable, accelerometer-based navigation for tibial alignment in total knee arthroplasty: a randomized, controlled trial: winner of the 2013 HAP PAUL award. J Arthroplast. 2014;29(2):288-94. https://doi.org/10.1016/j.arth.2 013.06.006.

16. Meneghini RM, Mont MA, Backstein DB, Bourne RB, Dennis DA, Scuderi GR. Development of a modern knee society radiographic evaluation system and methodology for Total knee arthroplasty. J Arthroplast. 2015;30(12):2311-4. https://doi.org/10.1016/j.arth.2015.05.049.

17. Konigsberg B, Hess R, Hartman C, Smith L, Garvin KL. Inter- and intraobserver reliability of two-dimensional CT scan for total knee arthroplasty component malrotation. Clin Orthop Relat Res. 2014;472(1):2127. https://doi.org/10.1007/s11999-013-3111-7.

18. Jenny JY, Barbe B. Small differences between anatomical and mechanical sagittal femur axes: a radiological and navigated study of 50 patients. Arch Orthop Trauma Surg. 2012;132(7):1053-7. https://doi.org/10.1007/s00402012-1500-0

19. Yoo JH, Chang CB, Shin KS, Seong SC, Kim TK. Anatomical references to assess the posterior tibial slope in total knee arthroplasty: a comparison of 5 
anatomical axes. J Arthroplast. 2008;23(4):586-92. https://doi.org/10.1016/j.a rth.2007.05.006.

20. Sarmah SS, Patel S, Hossain FS, Haddad FS. The radiological assessment of total and unicompartmental knee replacements. J Bone Joint Surg (Br). 2012;94(10):1321-9. https://doi.org/10.1302/0301-620x.94b10.29411.

21. Parratte S, Pagnano MW, Trousdale RT, Berry DJ. Effect of postoperative mechanical axis alignment on the fifteen-year survival of modern, cemented total knee replacements. J Bone Joint Surg Am. 2010;92(12): 2143-9. https://doi.org/10.2106/jbjs.l.01398.

22. Jeffery RS, Morris RW, Denham RA. Coronal alignment after total knee replacement. J Bone Joint Surg (Br). 1991;73(5):709-14.

23. Fang DM, Ritter MA, Davis KE. Coronal alignment in total knee arthroplasty: just how important is it? J Arthroplast. 2009;24(6 Suppl):39-43. https://doi. org/10.1016/j.arth.2009.04.034.

24. Insall JN, Dorr LD, Scott RD, Scott WN. Rationale of the knee society clinical rating system. Clin Orthop Relat Res. 1989;248:13-4.

25. Kuss O, Blettner M, Borgermann J. Propensity score: an alternative method of analyzing treatment effects. Dtsch Arztebl Int. 2016;113(35-36):597-603. https://doi.org/10.3238/arztebl.2016.0597.

26. Rassen JA, Shelat AA, Myers J, Glynn RJ, Rothman KJ, Schneeweiss S. Oneto-many propensity score matching in cohort studies. Pharmacoepidemiol Drug Saf. 2012;21:269-80. https://doi.org/10.1002/pds.3263.

27. Kang KT, Koh YG, Son J, Kwon OR, Park KK. Flexed femoral component improves kinematics and biomechanical effect in posterior stabilized total knee arthroplasty. Knee Surg Sports Traumatol Arthrosc. 2019;27(4):1174-81. https://doi.org/10.1007/s00167-018-5093-1.

28. Okamoto Y, Otsuki S, Nakajima M, Jotoku T, Wakama H, Neo M. Sagittal alignment of the femoral component and patient height are associated with persisting flexion contracture after primary Total knee arthroplasty. J Arthroplast. 2019;34(7):1476-82. https://doi.org/10.1016/j.arth.2019.02.051.

29. Scott CEH, Clement ND, Yapp LZ, MacDonald DJ, Patton JT, Burnett R. Association between femoral component sagittal positioning and anterior knee pain in Total knee arthroplasty: a 10-year case-control follow-up study of a cruciate-retaining single-radius design. J Bone Joint Surg Am. 2019; 101(17):1575-85. https://doi.org/10.2106/jbjs.18.01096.

30. Kim YH, Park JW, Kim JS, Park SD. The relationship between the survival of total knee arthroplasty and postoperative coronal, sagittal and rotational alignment of knee prosthesis. Int Orthop. 2014;38(2):379-85. https://doi. org/10.1007/s00264-013-2097-9.

31. Koenen P, Ates DM, Pfeiffer TR, Bouillon B, Bathis H. Femoral flexion position is a highly variable factor in total knee arthroplasty: an analysis of 593 conventionally aligned total knee replacements. Knee Surg Sports Traumatol Arthrosc. 2019;28(4):1014. https://doi.org/10.1007/s00167-01905548-6.

32. Maderbacher G, Schaumburger J, Baier C, Zeman F, Springorum HR, Birkenbach AM, et al. Appropriate sagittal femoral component alignment cannot be ensured by intramedullary alignment rods. Knee Surg Sports Traumatol Arthrosc. 2016;24(8):2453-60. https://doi.org/10.1007/s00167-01 5-3541-8.

33. Matassi F, Cozzi Lepri A, Innocenti M, Zanna L, Civinini R, Innocenti M. Total knee arthroplasty in patients with extra-articular deformity: restoration of mechanical alignment using accelerometer-based navigation system. J Arthroplast. 2019;34(4):676-81. https://doi.org/10.1016/j.arth.2018.12.042.

34. Malviya A, Lingard EA, Weir DJ, Deehan DJ. Predicting range of movement after knee replacement: the importance of posterior condylar offset and tibial slope. Knee Surg Sports Traumatol Arthrosc. 2009;17(5):491-8. https:// doi.org/10.1007/s00167-008-0712-x.

35. Kang KT, Kwon SK, Son J, Kwon OR, Lee JS, Koh YG. The increase in posterior tibial slope provides a positive biomechanical effect in posteriorstabilized total knee arthroplasty. Knee Surg Sports Traumatol Arthrosc. 2018;26(10):3188-95. https://doi.org/10.1007/s00167-018-4925-3.

36. Banks SA, Harman MK, Hodge WA. Mechanism of anterior impingement damage in total knee arthroplasty. J Bone Joint Surg Am. 2002;84:237-42. https://doi.org/10.2106/00004623-200200002-00004.

37. Iorio R, Bolle G, Conteduca F, Valeo L, Conteduca J, Mazza D, et al. Accuracy of manual instrumentation of tibial cutting guide in total knee arthroplasty. Knee Surg Sports Traumatol Arthrosc. 2013;21(10):2296-300. https://doi. org/10.1007/s00167-012-2005-7.

38. Goh GS, Liow MHL, Tay DK, Lo NN, Yeo SJ, Tan MH. Accelerometer-based and computer-assisted navigation in Total knee arthroplasty: a reduction in mechanical Axis outliers does not Lead to improvement in functional outcomes or quality of life when compared to conventional Total knee arthroplasty. J Arthroplast. 2018;33(2):379-85. https://doi.org/10.1016/j.arth.2 017.09.005.

39. Hasegawa M, Yoshida K, Wakabayashi H, Sudo A. Cutting and implanting errors in minimally invasive total knee arthroplasty using a navigation system. Int Orthop. 2013;37(1):27-30. https://doi.org/10.1007/s00264-012-1688-1.

40. Catani F, Biasca N, Ensini A, Leardini A, Bianchi L, Digennaro V, et al. Alignment deviation between bone resection and final implant positioning in computer-navigated total knee arthroplasty. J Bone Joint Surg Am. 2008; 90(4):765-71. https://doi.org/10.2106/jbjs.G.00293.

41. da Assunção RE, Hancock NJ, Bruce WJ, Walker P. The limits of precision in conventionally instrumented computer-navigated total knee arthroplasty. Knee Surg Sports Traumatol Arthrosc. 2012;20(12):2528-34. https://doi.org/1 0.1007/s00167-012-1952-3.

42. Fujimoto E, Sasashige Y, Nakata K, Yokota G, Omoto T, Ochi M. Technical considerations and accuracy improvement of accelerometer-based portable computer navigation for performing distal femoral resection in Total knee arthroplasty. J Arthroplast. 2017;32(1):53-60. https://doi.org/10.1016/j.arth.2 016.05.067.

43. Delp SL, Stulberg SD, Davies B, Picard F, Leitner F. Computer assisted knee replacement. Clin Orthop Relat Res. 1998;354:49-56. https://doi.org/10.1097/ 00003086-199809000-00007.

44. Shah SM, Sciberras NC, Allen DJ, Picard F. Technical and surgical causes of outliers after computer navigated total knee arthroplasty. J Orthop. 2020;1: 18171-6. https://doi.org/10.1016/j.jor.2019.10.016.

45. Mori S, Akagi M, Asada S, Matsushita T, Hashimoto K. Tibia vara affects the aspect ratio of tibial resected surface in female Japanese patients undergoing TKA. Clin Orthop Relat Res. 2013;471(5):1465-71. https://doi. org/10.1007/s11999-013-2800-6.

46. Sikorski JM. Alignment in total knee replacement. J Bone Joint Surg (Br). 2008;90(9):1121-7. https://doi.org/10.1302/0301-620x.90b9.20793.

47. D'Lima DD, Hermida JC, Chen PC, Colwell CW Jr. Polyethylene wear and variations in knee kinematics. Clin Orthop Relat Res. 2001;392:124-30. https://doi.org/10.1097/00003086-200111000-00015.

48. Green GV, Berend KR, Berend ME, Glisson RR, Vail TP. The effects of varus tibial alignment on proximal tibial surface strain in total knee arthroplasty: the posteromedial hot spot. J Arthroplast. 2002;17(8):1033-9. https://doi. org/10.1054/arth.2002.35796.

49. Werner FW, Ayers DC, Maletsky LP, Rullkoetter PJ. The effect of valgus/varus malalignment on load distribution in total knee replacements. J Biomech. 2005;38(2):349-55. https://doi.org/10.1016/j.jbiomech.2004.02.024.

50. Bellemans J, Colyn W, Vandenneucker H, Victor J. The Chitranjan Ranawat award: is neutral mechanical alignment normal for all patients? The concept of constitutional varus. Clin Orthop Relat Res. 2012;470(1):45-53. https://doi. org/10.1007/s11999-011-1936-5.

51. Hutt JR, LeBlanc MA, Massé V, Lavigne M, Vendittoli PA. Kinematic TKA using navigation: surgical technique and initial results. Orthop Traumatol Surg Res. 2016;102(1):99-104. https://doi.org/10.1016/j.otsr.2015.11.010.

52. Lee YS, Howell SM, Won YY, Lee OS, Lee SH, Vahedi H, et al. Kinematic alignment is a possible alternative to mechanical alignment in total knee arthroplasty. Knee Surg Sports Traumatol Arthrosc. 2017;25(11):3467-79. https://doi.org/10.1007/s00167-017-4558-y.

53. Keshmiri A, Maderbacher G, Baier C, Benditz A, Grifka J, Greimel F. Kinematic alignment in total knee arthroplasty leads to a better restoration of patellar kinematics compared to mechanic alignment. Knee Surg Sports Traumatol Arthrosc. 2019;27(5):1529-34. http://doi.org/. https://doi.org/10.1007/s00167018-5284-9.

54. Blakeney W, Clément J, Desmeules F, Hagemeister N, Rivière C, Vendittoli PA. Kinematic alignment in total knee arthroplasty better reproduces normal gait than mechanical alignment. Knee Surg Sports Traumatol Arthrosc. 2019;27(5):1410-7. https://doi.org/10.1007/s00167-018-5174-1.

55. McEwen PJ, Dlaska CE, Jovanovic IA, Doma K, Brandon BJ. Computerassisted kinematic and mechanical Axis Total knee arthroplasty: a prospective randomized controlled trial of bilateral simultaneous surgery. J Arthroplast. 2020;35(2):443-50. https://doi.org/10.1016/j.arth.2019.08.064.

56. An WG, Twiggs J, Leie $M$, Fritsch BA. Kinematic alignment is bone and soft tissue preserving compared to mechanical alignment in total knee arthroplasty. Knee. 2019;26(2):466-76. https://doi.org/10.1016/j.knee.2019.01.002.

57. Howell SM, Shelton TJ, Hull ML. Implant survival and function ten years after Kinematically aligned Total knee arthroplasty. J Arthroplast. 2018;33(12): 3678-84. https://doi.org/10.1016/j.arth.2018.07.020. 
58. Friedman RJ. Navigation in Total Knee Arthroplasty: A Procedure Whose Time Has Not Come: Commentary on an article by Young-Hoo Kim, MD, et al.: "The Clinical Outcome of Computer-Navigated Compared with Conventional Knee Arthroplasty in the Same Patients. A Prospective, Randomized, Double-Blind, Long-Term Study". J Bone Joint Surg Am. 2017; 99(12):e64. https://doi.org/10.2106/jbjs.17.00208.

59. Novak EJ, Silverstein MD, Bozic KJ. The cost-effectiveness of computerassisted navigation in total knee arthroplasty. J Bone Joint Surg Am. 2007; 89(11):2389-97. https://doi.org/10.2106/jbjs.F.01109.

60. Demir B, Ozkul B, Saygili MS, Cetinkaya E, Akbulut D. Deformity correction with total knee arthroplasty for severe knee osteoarthritis accompanying extra-articular femoral deformity: the results are promising. Knee Surg Sports Traumatol Arthrosc. 2018;26(11):3444-51. https://doi.org/10.1007/s00167-01 8-4920-8.

61. Kazemi SM, Shafaghi T, Minaei R, Osanloo R, Abrishamkarzadeh H, Safdari F. The effect of sagittal femoral bowing on the femoral component position in Total knee arthroplasty. Arch Bone Jt Surg. 2017;5(4):250-4.

\section{Publisher's Note}

Springer Nature remains neutral with regard to jurisdictional claims in published maps and institutional affiliations.

Ready to submit your research? Choose BMC and benefit from:

- fast, convenient online submission

- thorough peer review by experienced researchers in your field

- rapid publication on acceptance

- support for research data, including large and complex data types

- gold Open Access which fosters wider collaboration and increased citations

- maximum visibility for your research: over $100 \mathrm{M}$ website views per year

At $\mathrm{BMC}$, research is always in progress.

Learn more biomedcentral.com/submissions 